\title{
Environmental Safeguards at Urban Municipality Level under the Urban Infrastructure Investment Projects in Nepal: A Conceptual Clarity
}

\author{
Kabi Prasad Pokhrel* and Padma Kumar Mailalee \\ Tribhuvan University, Nepal
}

Submission: April 03, 2019; Published: April 22, 2019

*Corresponding author: Kabi Prasad Pokhrel, Professor, Tribhuvan University, Kathmandu, Nepal

Keywords: Environmental; Urban sustainability; Infrastructure; Degradation; Social equity; Natural systems

Abbrevations: EIA: Environment Impact Assessment; GEIA: General Environmental Impact Assessment; EA: Environmental Assessment; DUDBC: Department of Urban Development and Building Construction; UII: Urban Infrastructure Investment; EMP: Environmental Management Plan; MOUD: Ministry of Urban Development; EGDA: Environment and Green Development Agency

\section{The Context}

There is an increasing trend of people living in urban areas and raises the prospect of crowded, violent and unhealthy cities threatened by the escalation of social conflict, and intolerable environmental degradation, and the collapse of basic services. As an antidote to these economic, social, and environmental ills, city and regional planning regimes embodying urban sustainability must be constituted. There is no universal archetype, the sustainable city, but thousands of possible sustainable cities, for each city have unique historical, cultural, political, and environmental circumstances. However, planning regimes oriented towards urban sustainability can be adapted from approaches formulated in cities and regions where problems of infrastructure, social equity, and urbanization of the environment have been creatively addressed.

For this, visionary planner and urban planning procedures can meet the service needs of the general public while enhancing the naturalness of the urban environment. This can provide attention to designing an efficient and desirable intra-urban bus system, to expanding urban green space, and to meeting the basic needs of the urban population. It reveals that the goal of making cities greener to mitigate their impact on the environment can be embodied in infrastructure projects which make cities more livable for humans [1]. A nature friendly development plan is essential for the Federal Nepal in two ways. Firstly, the potential economic and social impacts of environmental degradation are particularly important for many urban municipalities. They (Municipalities) are the most vulnerable to climate change and tend to be more dependent than advanced economies on the ex ploitation of natural resources for economic growth. In addition, many they face severe economic, social and ecological threats from energy, food and water insecurity to climate change and extreme weather risks. It suggests us that we must plan in such a way in which economic growth protecting the integrity of natural systems. Thus, urban plan should begin the development process by asking which aspects of the natural environment should be saved from development and contains effective provisions for public participation. This can help how the natural environment, placed in its proper perspective, should act as both an opportunity for development and a constraint upon development adopting an integrated paradigm of social, economic and environmental sustainability of the urban life.

In recent decades, global concern has emerged about the non-renewability of natural resources as a factor limiting production and the threat to long-term economic growth caused by environmental destabilization and pollution. Economists have begun to address the question first posed by Malthus whether exponential growth in population and in resource use but only linear growth in technology and in subsistence is bound to lead to a social catastrophe\}in a word, whether the contemporary course of economic development is sustainable. The advent of sustainability in development science has led planners to apply evolving notions of sustainability to the contemporary debate over how cities and regions should be revitalized, redeveloped, and reformed. At present in Nepalese context, it is common in planning circles for urban planners to describe efforts to reverse problems of urban sprawl, congestion, and decline as a search for urban sustainability $[2,3]$. This is the case even though in urban theory no consensus exists as to which human settlements 
embody sustainability. Hence, for environmental planners, the pursuit of urban sustainability becomes a matter of placing the development of land into cities and the protection of natural systems into a state of vital equipoise [4]. It is as if city and regional planners have seized upon the ideal of sustainability as a tangible goal, a societal end-state, rather than properly viewing it as an organizing principle governing activity at all levels of an urban system, a process for selecting urban

Some urban planners envisioned the economic sustainability of a city, its potential to reach qualitatively a new level of socio-economic, demographic and technological output which in the long run reinforces the foundations of the urban system. While environmental activists, link urban sustainability to broader social principles of futurity, equity, and participation, especially involvement of public citizens in the land development process. Environmental planners speak of urban sustainability; they mean the pursuit of urban form that synthesizes land development and nature preservation. Hence, for environmental safeguard of urban sustainability becomes a matter of placing the development of land into cities and the protection of natural systems into a state of vital equipoise [5]. It is as if city and regional planners have seized upon the ideal of sustainability as a tangible goal, a particular societal end-state, rather than properly viewing it as an organizing principle governing activity at all levels of an urban system, a process for selecting urban alternatives that will yield vitality. Perhaps this confusion in planning circles about what urban sustainability would require stems from the fact that Agenda 21, the Earth Summit pact that addresses the sustainable development of cities, both mandates concrete planning measures and implies abstract concepts that should guide planning generally. This is not inconsistent; nonetheless, the tumult over sustainability in planning circles has tended to conflate planning guidelines, which are specific in nature and applicable on a case-by-case basis and planning principles, which, by definition, must be general and of universal applicability.

\section{Legal Provision}

The overarching policy on environmental resources and their protection is set out in the 2015 Constitution of Democratic Republican Nepal. Article 30 states the right to clean environment and mentioned that every citizen shall have the right to live in a clean and healthy environment and the victim shall have the right to obtain compensation, in accordance with law, for any injury caused from environmental pollution or degradation. Article 48 states the duties of every citizen to protect and preserve public property such as land, its subsoil, forests, water, fauna and flora and other natural resources that subject to the people's power and state protection. Article 51(f.2) states that the policy related to development should develop balanced, environment friendly, quality and sustainable physical infrastructures, while according priority to the regions lagging behind from development perspective, Article 51 (g-1) guaranteed every citizen to protect, promote, and make environmental friendly and sus- tainable use of, natural resources available in the country, in consonance with national interest and adopting the concept of inter- generational equity, and make equitable distribution of fruits, according priority and preferential right to the local communities and enjoy by the right to a healthy and safe environment, and to be protected against environmental pollution and ecological imbalance. Proceeding from, and conformable to, the Constitution, the Government of Nepal [6] has enacted a series of environmental laws, regulations and standards.

Environmental safeguards account the sustainable use of available natural and environmental resources including environmental impact assessment as defined in Asian Development Bank's (ADB)s safeguard policy statement (2009). All projects funded by ADB must comply with SPS 2009 to ensure that projects undertaken as part of programs funded under ADB loans are environmentally sound, are designed to operate in compliance with applicable regulatory requirements, and are not likely to cause significant environmental, health, or safety hazards. With respect to the environment, the SPS 2009 is underpinned by the ADB Operations Manual, Bank Policy [7].

In order to ensure conservation and sustainable use of environmental resources, the new Constitution of Nepal has granted every individual the right to live in a clean environment, but a fact that is to be kept in mind is that, unless and until the natural environment or various ecosystems are healthy, it cannot even be considered that the right to live in a clean environment can significantly be applied in practice. Hence, in Nepal's Constitution 2015, Article 30 the phrase every individual shall have the right to live in a clean and healthy environment in an inalienable manner. The fundamental right to live in a clean environment ensures the right of people living in suburban and urban areas, whereas the right to live in a healthy environment, along with preventing destruction of environmental resources such as trees and saplings, flora and fauna, rivers and streams, etc., shall help keep such environmental resources healthy, as a result of which, the present and future generations will be able to live in a clean and healthy environment for ages and can earn their livelihood by utilizing the environmental resources, goods and services. The communities earning their livelihood by being directly dependent on natural resources and that follow an environment-friendly lifestyle are bearing the brunt of the pollution and environmental degradation arising from physical infrastructure development such as industries, factories and other activities [8]. Thus, if the provision every citizen shall have the right to protection from suffering from environmental degradation and pollution and environmental policy, Act and Regulations in a disproportionate manner is incorporated in the fundamental rights, the communities pursuing an environment-friendly lifestyle can be free from the possibility of suffering from the adverse environmental effects in a disproportionate manner.

Under the Law on environmental safeguard or environment impact assessment (EIA), all development initiatives, whether 
new or renovation/expansion are to be the subject to general environmental impact assessment (GEIA) or environmental screening prior to implementation. The project proponent must submit the) project description,) technical and economic feasibility study, working drawings; and other relevant documents for screening by the appropriate authority.

\section{Approaches and Implication}

It is important to review the urban development programs at municipality level with explanation of the general anticipated environmental impacts of the tranches that should be financed under the proposed infrastructure investment programs to screening and categorization of sub-sequent tranches, assessment, and planning, including meaningful consultation with affected people and other stakeholders and information disclosure requirements. The environmental safeguard criteria that need to be used in selecting/rejecting subprojects and/or components under sub-sequent tranches and assess the adequacy of the borrower's capacity to implement national laws and Asian Development Bank's (ADB) requirements and identifies needs for capacity building. At the implementation level, procedures including the budget, institutional arrangements, and capacity development need to be rigorously analyzed. Monitoring and reporting system is required with the description of the responsibilities of the environmental assessment (EA) and of ADB in relation to the preparation, implementation, and progress review of safeguard documents of subsequent tranches.

Department of Urban Development and Building Construction (DUDBC) envisions the environmental safeguard in urban infrastructure investment (UII) to support the urban sustainability in the country by establishing a network of well-developed urban centers providing jobs, housing, and economic opportunities and urban services, with low impact on the environment, in the process improving the living conditions of the residents. Thus, the urban infrastructure investment program (UIIP) is geographically targeted with multi sector interventions to upgrade priority physical infrastructures and basic urban services, socio-economic facilities, and initiate a spatial transformation of the urban fabric. This approach could create more centrality and densification, attracting private business, and enabling better mixed land uses.

The policy promotes international good practice as reflected in internationally recognized standards such as the World Bank Group's Environmental, Health and Safety Guidelines as follows:

a) Use a screening process for each proposed project, as early as possible, to determine the appropriate extent and type of environmental assessment so that appropriate studies are undertaken commensurate with the significance of potential impacts and risks.

b) Conduct an environmental assessment for each proposed tranche to identify potential direct, indirect, cumulative, and induced impacts and risks to physical, biological, socioeconomic (including impacts on livelihood through environmental media, health and safety, vulnerable groups, and gender issues), and physical cultural resources in the context of the project's area of influence. Assess potential transboundary and global impacts, including climate change. Use strategic environmental assessment where appropriate.

c) Examine alternatives to the project's location, design, technology, and components and their potential environmental and social impacts and document the rationale for selecting the particular alternative proposed. Also consider the no project alternative.

d) Avoid, and where avoidance is not possible, minimize, mitigate, and/or offset adverse impacts and enhance positive impacts by means of environmental planning and management. Prepare an environmental management plan (EMP) that includes the proposed mitigation measures, environmental monitoring and reporting requirements, related institutional or organizational arrangements, capacity development and training measures, implementation schedule, cost estimates, and performance indicators. Key considerations for EMP preparation include mitigation of potential adverse impacts to the level of no significant harm to third parties, and the polluter pays principle.

e) Carry out meaningful consultation with affected people and facilitate their informed participation. Ensure women's participation in consultation. Involve stakeholders, including affected people and concerned nongovernment organizations, early in the project preparation process and ensure that their views and concerns are made known to and understood by decision makers and taken into account. Continue consultations with stakeholders throughout project implementation as necessary to address issues related to environmental assessment. Establish a grievance redress mechanism to receive and facilitate resolution of the affected people's concerns and grievances regarding the project's environmental performance.

f) Disclose a draft environmental assessment (including the EMP) in a timely manner, before project appraisal, in an accessible place and in a form and language(s) understandable to affected people and other stakeholders. Disclose the final environmental assessment, and its updates if any, to affected people and other stakeholders.

g) Implement the EMP and monitor its effectiveness. Document monitoring results, including the development and implementation of corrective actions, and disclose monitoring reports.

h) Do not implement project activities in areas of critical habitats, unless

(i) There are no measurable adverse impacts on the critical habitat that could impair its ability to function, 
(ii) There is no reduction in the population of any recognized endangered or critically endangered species, and

(iii) Any lesser impacts are mitigated. If a project is located within a legally protected area, implement additional programs to promote and enhance the conservation aims of the protected area. In an area of natural habitats, there must be no significant conversion or degradation, unless

(i) Alternatives are not available,

(ii) The overall benefits from the project substantially outweigh the environmental costs, and

(iii) Any conversion or degradation is appropriately mitigated. Use a precautionary approach to the use, development, and management of renewable natural resources.

i) Apply pollution prevention and control technologies and practices consistent with international good practices as reflected in internationally recognized standards such as the World Bank Group's Environmental, Health and Safety Guidelines. Adopt cleaner production processes and good energy efficiency practices. Avoid pollution, or, when avoidance is not possible, minimize or control the intensity or load of pollutant emissions and discharges, including direct and indirect greenhouse gases emissions, waste generation, and release of hazardous materials from their production, transportation, handling, and storage. Avoid the use of hazardous materials subject to international bans or phase-outs. Purchase, use, and manage pesticides based on integrated pest management approaches and reduce reliance on synthetic chemical pesticides.

j) Provide workers with safe and healthy working conditions and prevent accidents, injuries, and disease. Establish preventive and emergency preparedness and response measures to avoid, and where avoidance is not possible, to minimize, adverse impacts and risks to the health and safety of local communities. k) Conserve physical cultural resources and avoid destroying or damaging them by using field-based surveys that employ qualified and experienced experts during environmental assessment. Provide for the use of chance find procedures that include a pre-approved management and conservation approach for materials that may be discovered during project implementation.

Depending on the type of project, scale of a project, and population size of project location, GEIA needs to be conducted by the Ministry of Urban Development (MOUD) or the concerned local administrative body through DUDBC for a images and environment and green development agency (EGDA) for the Municipality of Nepal. However, the project must be comprised of two or more activities, as in the case of a tranche under this program, and GEIA can be conducted by the MOUD.

\section{References}

1. OECD (2012) Green growth and developing countries: A summary for policy makers: OECD.

2. Nepal Rastra Bank (NRB) (2018) Guideline on environmental and social risk management (ESRM) for banks and financial institutions. Kathmandu, Nepal.

3. Ministry of Urban Development (MOUD) (2017) National urban development strategy (NUDS). Kathmandu: MOUD/Urban Development and Physical Planning Division, Government of Nepal, Nepal.

4. Lyle JT (1994) Regenerate design for sustainable development. John Wiley \& Sons, Inc, New York, USA.

5. Basiago AD (1996) The search for the sustainable city in 20th century urban planning. The Enron mentalist 16(2): 135-155.

6. Government of Nepal (GON) (2015) Constitution of Democratic Republican Nepal. Kathmandu, Nepal.

7. Asian Development Bank (ADB) (2013) Environmental operational direction, 2013-2020: promoting transitions to green growth in Asia and the Pacific. Mandaluyong City, Philippines.

8. Moulaert F, Jessop B, Mehmood A (2016) Agency, structure, institutions, discourse (ASID) in urban and regional development. International Journal of Urban Sciences 5934: 1-21.

This work is licensed under Creative Commons Attribution 4.0 License DOI: 10.19080/IJESNR.2019.18.555993

\section{Your next submission with Juniper Publishers will reach you the below assets}

- Quality Editorial service

- Swift Peer Review

- Reprints availability

- E-prints Service

- Manuscript Podcast for convenient understanding

- Global attainment for your research

- Manuscript accessibility in different formats

( Pdf, E-pub, Full Text, Audio)

- Unceasing customer service

Track the below URL for one-step submission https://juniperpublishers.com/online-submission.php 